\title{
Minimally disruptive medicine: the evidence and conceptual progress supporting a new era of healthcare
}

\author{
${ }^{1} \mathrm{AM}$ Abu Dabrh ${ }^{*}{ }^{2} \mathrm{~K}$ Gallacher*, ${ }^{3} \mathrm{KR}$ Boehmer, ${ }^{4} \mathrm{IG}$ Hargraves, ${ }^{5} \mathrm{FS}$ Mair \\ ${ }^{1}$ Research Associate, ${ }^{3}$ Health Services Analyst, ${ }^{4}$ Service Designer, Mayo Clinic, Rochester, MN, USA; ${ }^{2}$ Fellow, ${ }^{5}$ Professor of Primary Care \\ Research, Institute of Health and Wellbeing, University of Glasgow, Glasgow, UK \\ *joint first authors
}

\begin{abstract}
Patients with chronic conditions or multimorbidity, and often their caregivers, have to adjust their lives and mobilise their capacity (ability) to respond to the workload (demands) imposed by treatments and the care of their conditions. There is a continuous and complex interaction between workload and capacity. When capacity proves insufficient to address the treatment workload, creating a burden, patients may place a lower priority on other aspects of their lives, or reduce engagement with healthcare. Guidelines usually focus on diseasecentred outcomes without consideration of limited capacity or demanding workload (burden) from treatment regimens. It seems reasonable to consider that healthcare needs reshaping so that care that pursues goals important to patients as well as those suggested by evidence-based medicine. This can be achieved by using shared decision approaches guided by the expertise of clinicians to deliver optimal care while minimising the burden of treatment on patients, their caregivers, and the healthcare system. What we need is minimally disruptive medicine.
\end{abstract}

Correspondence to F Mair Institute of Health and Wellbeing College of Medical, Veterinary and Life Sciences

University of Glasgow

I Horselethill Road Glasgow GI 2 9LX

UK

e-mail frances.mair@glasgow.ac.uk

KEYWORDS burden, capacity, chronic, MDM, minimally disruptive medicine, workload

DECLARATION OF INTERESTS No conflict of interest declared

\section{INTRODUCTION}

In this era of modern medicine, there has been a welldocumented rise in the prevalence of chronic conditions and multimorbidity. ${ }^{1,2}$ This rise has been accompanied by a proliferation of treatment options and advances in clinical outcomes, but also by an increase in demands and potential challenges for patients. A continuous focus on disease-centred clinical care and guideline development, as well as a population-level oriented approach to disease management, has resulted in a lack of insight into whether the needs of patients with multimorbidity and chronic disease are met effectively by health services. ${ }^{3,4}$ Guidelines focus on clinical outcomes without taking consideration of the capacity, abilities and limitations of patients to manage their daily care. They also discount the workload, demands and responsibilities that accompany these treatment regimens. The continuous and complex interaction between workload and capacity is fluid and sensitive to changes in the individual, their health, social networks and environment. By neglecting this balance, diseasecentred approaches may inadvertently increase the risk of adverse events and result in poorly co-ordinated, fragmented care. ${ }^{3,4}$ Healthcare needs reshaping, and a new era of medicine is evolving: minimally disruptive medicine (MDM). ${ }^{5}$ Here we describe the emerging evidence base behind this exciting new concept, by discussing: i) the workload of healthcare for patients; ii) why individual capacity can affect outcomes; iii) the challenges posed by multimorbidity: and iv) the role of MDM in addressing these issues.

\section{THE WORK OF HEALTHCARE FOR PATIENTS}

Patients with long term conditions often face considerable encumbrance from their illness, for example physical symptoms, psychological difficulties and financial hardship due to lost employment. Alongside this burden of illness there is another hardship that is often overlooked, the burden of treatment (BOT). This multi-dimensional phenomenon describes the added and ongoing workload (i.e. requirements and demands) for patients in order for them to adhere to recommendations made by their clinicians to manage their morbidity and wellbeing. ${ }^{6}$ It also reflects the barriers patients face as they navigate through this journey of healthcare. Treatment workload encompasses the tasks carried out by patients to manage their illness (e.g. taking medications, reading information leaflets, arranging transportation to appointments, making lifestyle changes). ${ }^{6,7}$ The BOT is likely to be affected by the nature of the illness and treatments available (e.g. number and frequency of visits, managing transportation), presence of comorbidities (each comorbidity adds visits to the clinic, claim forms, 
medications and paper work) and, importantly, the organisation of health services and the practices of health practitioners. ${ }^{5,8,9}$ The BOT is likely to vary between places due to differences in healthcare settings or systems. For example, financial obstacles are more likely to be found in healthcare systems that require patients to negotiate with insurers (such as in the US) than in universal healthcare systems where care is free at the point of contact (such as in the UK). ${ }^{10}$

There has been a recent shift towards self-management and community rehabilitation with the aim of cutting costs and improving patient outcomes; ${ }^{11,12}$ however these changes are likely to fundamentally shift the work of treatment from health professionals towards patients and their caregivers. In response to these changes, patients and their caregivers may make considerable efforts to minimise burdens imposed on them by health systems, further adding to their everyday workload (utilising social networks, using problem based strategies and relying on emotion based coping techniques)..$^{13}$ Identifying this burden may help clinicians better understand the demands that follow from their recommendations and help patients to better manage and adhere to proposed regimens.

There is growing evidence of BOT for those with chronic conditions. Patient-reported measures have been used to quantify aspects of BOT in various conditions such as diabetes, chronic heart failure, cancer, chronic obstructive pulmonary disease and cystic fibrosis. Types of measured BOT include time and effort spent following medication regimes, ${ }^{14}$ side effects of treatment, ${ }^{15}$ and out-of-pocket expenditure. ${ }^{16} \mathrm{~A}$ recent systematic review examined patient reported measures of BOT in chronic heart failure, diabetes and chronic kidney disease and found that the majority of studies lacked direct patient input and did not show evidence of reliability of the measures used. ${ }^{17}$ However, there has been recent interest in the development of more broadly focused patient-reported measures. ${ }^{6,18,19}$ These measurements look promising and are currently being validated in different populations and settings. A plethora of qualitative work has also appeared in the literature, exploring the patient experience of treatment burden in stroke, chronic heart failure, end of life care, and multimorbidity. ${ }^{720-22}$ This qualitative work complements the aforementioned quantitative work, both by informing the development of measures of BOT and also by supplying deeper insight into the patient perspective.

\section{PATIENT CAPACITY}

Capacity refers to the abilities and resources the patient can mobilise to address, manage, and cope with the demands of healthcare and life..$^{23}$ If capacity is limited or capped then this impacts on the 'ability or readiness of the individual to do work' ${ }^{23}$ Capacity relates to a range of areas of patients' lives, such as their available time and their personal, physical, emotional, social, environmental, and financial capacity. Accompanying the concept of treatment burden is the acknowledgement that there is considerable variation between patients with regards their capacity to cope with a given treatment workload, depending on social support systems and other personal commitments. It is well recognised that an individual's ability to follow treatments and engage with health professionals can be affected by both environmental factors such as social support and financial constraints ${ }^{24}$ and internal factors such as health literacy and resilience. ${ }^{25}$ Similarly to BOT, the conceptualisation of patient capacity has preceded the development of methods of measurement. However, certain available patient reported measures do consider aspects of capacity, including self-efficacy and the intrusion of illness on everyday life ${ }^{26}$ or the effects of disabilities such as visual or hearing impairments. ${ }^{27}$ Capacity influences health and vice versa. In a recent systematic review, supporting patient capacity in interventions was associated with greater effectiveness in reducing 30 -day hospital readmissions. ${ }^{28}$

\section{THE (IM)BALANCE BETWEEN CAPACITY AND WORKLOAD}

Workload and capacity are interrelated and may be in balance or imbalance with one another as the Cumulative Complexity Model describes (Figure I). ${ }^{23}$ This model makes apparent the self-reinforcing cycle in which adding treatment to patients with high workload and low capacity may diminish self-care, adherence to therapies, quality of life, and health outcomes. The concepts of workload and patient capacity have been further conceptualised by development of Burden of Treatment Theory. ${ }^{8}$ This theorises healthcare utilisation as an undertaking that is characterised by individuals and their support networks navigating through health services and their associated clinicians.

Along with their support networks, individuals possess the ability to perform healthcare tasks, secure co-operation of others and add to their social capital, thus reinforcing the resilience of their network. This emphasises the relational aspects of healthcare provision and the importance of resources for both clinicians and patient, with maximum benefits only being gained from services if patients are given the wherewithal to use them.

\section{MULTIMORBIDITY}

One important factor that affects the workload-capacity balance is the presence and extent of multimorbidity. ${ }^{18}$ Those with multiple conditions are more likely to have diminished capacity due to associated factors such as poor physical and mental health, including the effects of burden of symptoms, lack of employment and higher 


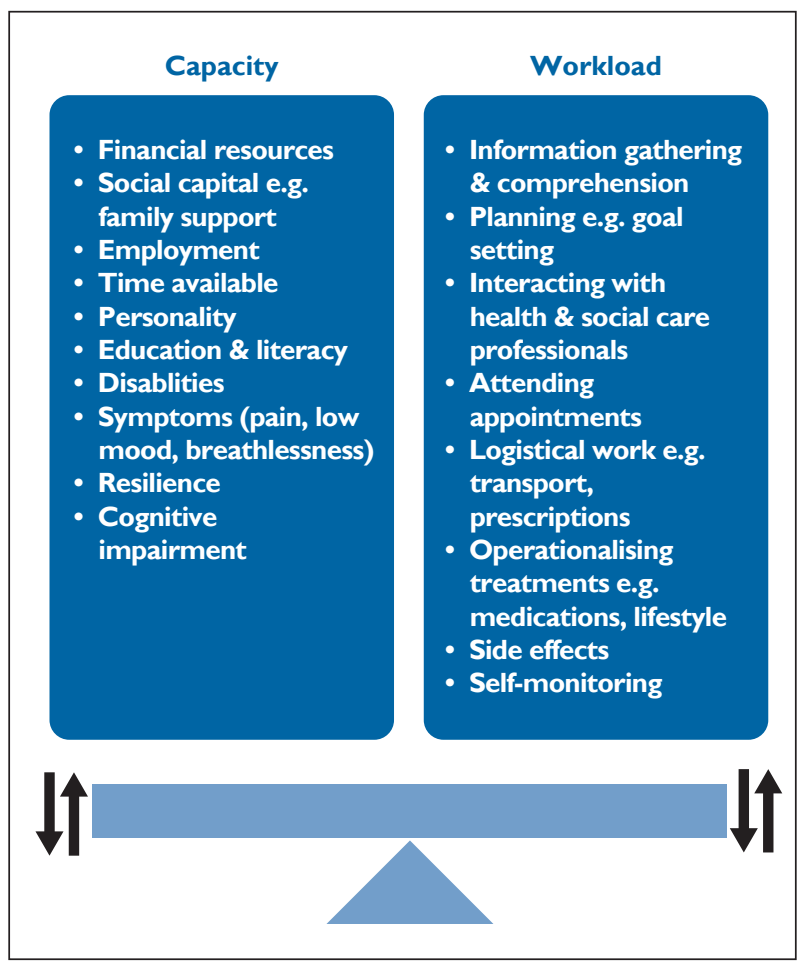

FIGURE I Determinants of capacity and workload on either side of a balanced scale. If a patient's capacity is large enough to cope with their workload then there is equilibrium. When workload outweighs capacity the balance is lost and negative outcomes occur.

levels of deprivation. Treatment burden is also likely to be increased due to, for example, higher numbers of treatments and polypharmacy, increased risk of adverse events and poorly co-ordinated care. Consideration of comorbidities is therefore vital when assessing and managing workload and implementing support for those with long term conditions. ${ }^{2}$

\section{THE CASE FOR MINIMALLY DISRUPTIVE MEDICINE}

The complex interaction of disease, treatment, and experience in multimorbid patients suggests that the appropriate unit of treatment is not each condition considered separately or even combined.The appropriate focus of treatment is the situation and the individual tackled as a whole. Concepts such as workload, burden and capacity direct attention to the situation in which the patient and their carers exist while living with illness. Importantly, these concepts also direct our attention to issues which healthcare and clinicians are often blindthe extent to which a healthcare-created burden inadvertently drags people down.

Minimally disruptive medicine is a patient-centred approach that asks the question; what is the situation that demands medicine, and, what is the medicine that the situation demands? $?^{29}$ In attending to the patient's unique situation and morbidity, MDM recognises that guidelines and standard processes only partially address the key issues for any given individual. Such guidelines are useful hypotheses for approaching practice, but they should be interrogated in terms of how they serve the person at hand. In considering the situation through the lens that guidelines or routine treatments and tests provide, questions about the feasibility, viability and desirability of treatment must be asked. In approaching the feasibility of treatment, MDM considers if and how it is possible to instigate a considered intervention, for instance; does the patient have the necessary capacity and relational support to undertake the work of treatment, and are the limited resources of real healthcare settings appropriately acknowledged in passing the work of treatment on to patients? Viability goes beyond asking if it is possible to instigate treatment in the short term but to consider the longitudinal aspects of an intervention - what would life look like with this treatment in place, is it sustainable and at what cost, how might it change over time? Desirability asks necessary questions of the value of a considered treatment plan - who recognises the intervention as desirable, what is the hoped for value of the intervention in the patient's life?

When standard practices and guidelines do not adequately answer these questions, invention and adaptation are necessary. These may include approaches to maximise the benefit of limited healthcare or patient resources, reshaping the working relationship of patient and clinicians, adjusting goals, shared decision making, streamlining medication regimens, and strengthening relationships with the community. An exemplar MDM toolkit is available, with tools such as 'goal elicitation', 'capacity assessments', 'workload assessments' ,'resource registries' and 'medication therapy management tool'..$^{30}$ These tools and others in development provide patients and clinicians with practical means to do justice to the question of patient-centred care.

To enable the practice of MDM, particularly in pay-for -performance-systems, guidelines should be amended to take account of multimorbidity and incentives should be created for well-coordinated care that minimises treatment burden for patients. ${ }^{9}$ Over the past decade, there has been a call for the practice of more thoughtful care for patients and the call for MDM complements this notion. ${ }^{6}$ It encourages clinicians to provide holistic care that realistically considers the burdens imposed on patients from healthcare systems and other aspects of their life. Some of these changes will require considerable investment from governing bodies, but MDM is designed to be a cost-effective way of caring for patients, as wasted resources are minimised and healthcare utilisation is rationalised. The aforementioned evidence suggests that by practising MDM, we can not only improve outcomes but also reduce preventable healthcare utilisation such as readmission to hospital. ${ }^{28}$ 
Here we have outlined the evidence base behind MDM, a new way of delivering healthcare from the clinical consultation to the creation of guidelines and healthcare policy. Minimally disruptive medicine is exciting and innovative in that it is designed to provide comprehensive, evidence-based, supportive care that fits into the patient's life. It opens an honest dialogue with patients about how they are coping with their illness and

\section{REFERENCES}

I Alwan A, Maclean DR, Riley LM et al. Monitoring and surveillance of chronic non-communicable diseases: progress and capacity in highburden countries. Lancet 20I0; 376: I86I-8. http://dx.doi. org/I0.10I6/S0I40-6736(I0)6I853-3

2 van den Akker M, Buntinx F, Metsemakers JF et al. Multimorbidity in general practice: prevalence, incidence, and determinants of co-occurring chronic and recurrent diseases. J Clin Epidemiol 1998; 5I: 367-75.

3 Fraccaro P, Arguello Casteleiro M, Ainsworth J et al. Adoption of clinical decision support in multimorbidity: a systematic review.JMIR Med Inform 20I5; 3: e4. http://dx.doi.org/I0.2196/medinform.3503

4 Mutasingwa DR, Ge H, Upshur RE. How applicable are clinical practice guidelines to elderly patients with comorbidities? Can Fam Physician 201 I; 57: e253-62.

5 May C, MontoriVM, Mair FS.We need minimally disruptive medicine. BMJ 2009; 339: b2803. http://dx.doi.org/I0.I I36/bmj.b2803

6 Eton DT, Ridgeway JL, Egginton JS et al. Finalizing a measurement framework for the burden of treatment in complex patients with chronic conditions. Patient Relat Outcome Meas 20I5; 6: II7-26. http://dx.doi.org/I0.2 I47/PROM.S78955

7 Gallacher K, May CR, Montori VM et al. Understanding patients' experiences of treatment burden in chronic heart failure using normalization process theory. Ann Fam Med 20I I; 9: 235-43. http:// dx.doi.org/l0.1370/afm. I249

8 May CR, Eton DT, Boehmer K et al. Rethinking the patient: using Burden of Treatment Theory to understand the changing dynamics of illness. BMC Health Serv Res 20I4; 14: 28I. http://dx.doi. org/I0.I I86/I472-6963-|4-28I

9 Mair FS, May CR.Thinking about the burden of treatment. BMJ 20I4; 349: g6680. http://dx.doi.org//0.I I 36/bmj.g6680

10 The Department for Professional Employees AFL-CIO. The U.S. Health Care System:An International Perspective. 2014. http://dpeaflcio. org/the-u-s-health-care-system-an-international-perspective (accessed I/4/20I5).

II Tyreman S. The expert patient: outline of UK government paper. Med Health Care Philos 2005; 8: I49-5I.

I2 Fjaertoft H, Rohweder G, Indredavik B. Stroke unit care combined with early supported discharge improves 5-year outcome: a randomized controlled trial. Stroke 20I I; 42: I707-I I. http://dx.doi. org/I0.I I6I/STROKEAHA. II 0.601 I53

13 Ridgeway JL, Egginton JS, Tiedje $\mathrm{K}$ et al. Factors that lessen the burden of treatment in complex patients with chronic conditions: a qualitative study. Patient Prefer Adherence 20I4; 8: 339-5I. http://dx. doi.org/I0.2I47/PPA.S580I4

14 Jowsey T, Yen L, W PM. Time spent on health related activities associated with chronic illness: a scoping literature review. BMC Public Health 2012; 12: 1044. http://dx.doi.org/I0.I I86//47I-2458I2-I044

I5 Bernhard J, Maibach R, Thürlimann B et al. Patients' estimation of overall treatment burden: why not ask the obvious? J Clin Oncol 2002; 20: 65-72.

16 Islam MM, Yen L, Valderas JM et al. Out-of-pocket expenditure by Australian seniors with chronic disease: the effect of specific diseases and morbidity clusters. BMC Public Health 2014; 14: 1008. http://dx.doi.org//0.1/86/I47/-2458-14-1008 treatment. Rather than following disease-centred guidelines and targets, goals are shifted towards improving patient wellbeing and valuing an individuals' capacity to pursue their life's hopes and dreams. Minimally disruptive medicine is not just a novel way of thinking; it is a way forward in caring, and one that will transform healthcare as we know it.

17 Eton DT, Elraiyah TA, Yost KJ et al. A systematic review of patientreported measures of burden of treatment in three chronic diseases. Patient Relat Outcome Meas 2013; 4: 7-20. http://dx.doi. org/I0.2I47/PROM.S44694

18 Tran VT, Montori VM, Eton DT et al. Development and description of measurement properties of an instrument to assess treatment burden among patients with multiple chronic conditions. BMC Med 2012; 10: 68. http://dx.doi.org/I0.1/86/I741-7015-10-68

19 Ridgeway JL, Beebe TJ, Chute CG et al. A brief Patient-Reported Outcomes Quality of Life (PROQOL) instrument to improve patient care.PLoS Med 20 I 3; I0: e I00 I 548. http://dx.doi.org/I0. I37I/ journal.pmed. I00I548

20 Jani B, Blane D, Browne S et al. Identifying treatment burden as an important concept for end of life care in those with advanced heart failure. Curr Opin Support Palliat Care 2013; 7: 3-7. http://dx.doi. org/I0.1097/SPC.0b0 I3e32835c07I1

2I Sav A, Kendall E, McMillan SS et al. 'You say treatment, I say hard work': treatment burden among people with chronic illness and their carers in Australia. Health Soc Care Community 2013; 21 : 66574. http://dx.doi.org//0.1 I I I/hsc. 12052

22 Gallacher K, Morrison D, Jani B et al. Uncovering treatment burden as a key concept for stroke care: a systematic review of qualitative research. PLoS Med 2013; 10: el001473. http://dx.doi.org/I0.137I/ journal.pmed.I00I473

23 Shippee ND, Shah ND, May CR et al. Cumulative complexity: a functional, patient-centered model of patient complexity can improve research and practice. J Clin Epidemiol 20I2; 65: I04I-5I. http://dx.doi.org/I0.10I6/j.jclinepi.20I2.05.005

24 Vassilev I, Rogers A, Sanders C et al. Social networks, social capital and chronic illness self-management: a realist review. Chronic IIIn 20I I; 7: 60-86. http://dx.doi.org/I0.II77/I7423953/0383338

25 Furniss D, Barber N, Lyons I et al. Unintentional non-adherence: can a spoon full of resilience help the medicine go down? BMJ Qual Saf 20I4; 23: 95-8. http://dx.doi.org/ I0.I I36/bmjqs-20 I3-002276

26 Lorig KR, Sobel DS, Ritter PL et al. Effect of a self-management program on patients with chronic disease. Eff Clin Pract 200I; 4: 256-62.

27 Richardson J, lezzi A, Khan MA et al. Validity and reliability of the Assessment of Quality of Life (AQoL)-8D multi-attribute utility instrument. Patient 20 I4; 7:85-96. http://dx.doi.org/I0.I007/s4027I0I3-0036-x

28 Leppin AL, Gionfriddo MR, Kessler M et al. Preventing 30-day hospital readmissions: a systematic review and meta-analysis of randomized trials. JAMA Intern Med 2014; 174: 1095-II07. http:// dx.doi.org//0.100I/jamainternmed.20I4.1608

29 Jafarinaimi N, Nathan L, Hargraves I. Values as hypotheses: design, inquiry, and the service of values. Design Issues 2015; in press.

30 Leppin A MV, Gionfriddo M. Minimally Disruptive Medicine: A Pragmatically Comprehensive Model for Delivering Care to Patients with Multiple Chronic Conditions. Healthcare 20I5; 3: 50-63. http:// dx.doi.org/I0.3390/healthcare3010050 